\title{
Animal Behavior in a Fully Automatically Controlled
}

\section{Dairy Farm}

\author{
Anja Gräff ${ }^{1}$, Renate Luise Dörfler ${ }^{1}$, Manfred Höld ${ }^{2}$, Jörn Stumpenhausen ${ }^{2}$ and Heinz Bernhardt ${ }^{1}$ \\ 1. Technische Universität München, Center of Life and Food Sciences, Agricultural Systems Engineering, Am Staudengarten 2, \\ D-85354 Freising-Weihenstephan, Germany \\ 2. Hochschule Weihenstephan-Triesdorf, University of Applied Sciences Weihenstephan-Triesdorf, Faculty of Agricultural and \\ Nutritional Sciences, Am Hofgarten 1, D-85354 Freising-Weihenstephan, Germany
}

\begin{abstract}
As there are increasing numbers of small farms in Germany, it is necessary for them, to keep the workload as small as possible by enhancing the use of automatism. Important as those energetic-technical capabilities and features in a modern dairy farm are, the final decision when using automatic machinery depends on the animal itself and its behavior. As a result, all animal-physiological criteria, animal protection and animal welfare have to be taken into consideration. Therefore tests have been done to investigate dairy cattle behavior on suddenly occurring energy failures, fluctuations or postponements due to a load management. The experiments have been taken in four different stables. In each stable, 12 "focus cows" have been selected. Their daily stress response was measured by a heart rate monitor and faecal cortisol metabolites. Video observation showed modifications in behavior, escape or avoidance reactions; pedometers recorded the movement activity. These scientific experiments will demonstrate cattle behavior in situations driven by a power load management, but no statistically significant effects on the usual daily routine are being expected.
\end{abstract}

Key words: Cattle behavior, cortisol, heart rate variability, power load management, smart grid, Germany.

\section{Introduction}

\subsection{Background}

The nuclear disaster of Fukushima in 2011 has led to the phasing-out of nuclear energy in Germany until 2022 and has initiated therefore the change towards sustainability.

Hence, the German Federal Government will address the following specific objectives: to increase the share of renewable energy of almost 25\% (2012) up to $45 \%$ by 2025 and up to $60 \%$ by 2035 [1]. To avoid far energy transports, the German government promotes regional renewable energy concepts.

In addition, energy from small-sized wind energy plants, photovoltaic and biogas will be increasingly fed in a decentralized way by private households,

Corresponding author: Anja Gräff, M.Sc., research field: interaction of robot systems with farm animals. E-mail: anja.graeff@wzw.tum.de. agricultural operations and other investors in renewable energy into the grid. This will change the electricity grid from its original function as a pure electrical distribution network to an electricity grid, which can transport electrical power in both directions.

The transmission system operators for electricity must guarantee net stability despite varying supply according to sunshine duration or wind force. The main method to store excessive energy currently in use is with pumped-storage power plants. Today, battery storage technology is almost fit for series production.

However, it must also be considered how the energy at consumer level can be used "intelligently”, i.e., how peak currents can be avoided in consumption in standalone operation as well as for the energy fed into the grid. This also applies for dairy farms. On the one hand, the agricultural businesses produce energy 
with photovoltaic-systems on stable and hall roofs, with small-sized wind energy plants and with biogas plants. On the other hand, the dairy farm with increasing mechanization or automation is a power consumer.

While photovoltaic-systems and small-sized wind energy plants produce energy only as a function of sunshine duration or with sufficient wind speed, biogas plants can also be used to store energy. Biogas, set free by fermentation, can be stored and burnt in engines at times of electricity demand. Then the powered generators produce electricity to either cover personal use or to feed into the public power grid if necessary, because there are still no technically highly developed power storage devices on the market.

Hence, agriculture with livestock is predestined like no other economic sector for producing renewable energy. An intelligent on-farm smart-grid is necessary to use this renewable energy optimally with a high own consumption portion. Electricity producers, electricity consumers and electricity storage must be integrated into the system.

Apart from this, the specific features of milk production (two times milking a day at intervals of $12 \mathrm{~h}$ with a high energy demand at the milking sessions) cause very specific technical demands for such a comprehensive energy management system: the introduction of permanently active milking robots, which substitute the traditional handicrafts in German dairy cattle more and more, has evened out energy consumption. The two typical peaks of energy are no longer apparent. This opened up the possibility to cover the basic load by for example small-sized wind energy plants or photovoltaic systems at least at some times.

In Germany, the use of milking robots clearly increases. Also a strong trend of automation is to be recognized in the whole stable management. New dairy cattle are equipped almost exclusively with automatic feeding, manure removal and bedded systems as well as milking robots, while common stables are retrofitted step by step.

The electricity users show various load profiles with dairy cattle, which are to be prioritized differently. Thus, for example, an automatic milking system (AMS) must constantly have energy, whereas a cow brush can sometimes stand still for a few hours. The mobile barn cleaner cannot operate during feeding time, when the feeding alley is being visited by many cows. In practice, this requires a higher level of communication among all components of the whole system comparable to industrial cyber-physical production systems (project for the future "industry $4.0 ”)$.

By specific load management (smart-grid), the energy costs should be lowered by misalignment and locking of consumers. However, this can mean that exactly the introduction phase of such a load management might enforce energy failures.

\subsection{Objective}

A differentiated on-farm-energy management system will form the basis. This should link different producers of renewable energies (roof-mounted photovoltaic system, small-sized wind energy plants, compact farm biogas plants, near-surface geothermal energy) with smart-grid capable consumers and optional energy storages (batteries, ice-storage milk cooling, hot water and compressed-air energy storage) in modern sustainable dairy cattle system-technically. And one hopes for reasons of the single-operational economic efficiency and the resource protection to achieve an optimum of an own domestic consumption rate. Besides, an optimum regional network load should be promoted by creation of an intelligent network connection.

The available energy determines the flexible use of the robot systems during the day. Because no stable daily rhythm could be established, this could have effects on the animal behavior.

The aim of this sub-project research consists therefore in quantifying possible load reactions of 
milk cows with the energy-conditioned failure of milking robots. To be able to recognize load reactions, the stress measurement is applied. As stress indicators heart activity, cortisol metabolites level and behavior are to be measured.

These indicators should show possible changes between the basic measurement and the test measurement, i.e., whether by a milking claim refusal through AMS (simulates a stream failure) compared to the normal mode of the AMS, changes appear.

\subsection{Foundations}

\subsubsection{On-Farm Energy Management}

An energy management system shall use the produced energy as much as possible for the own farm, so that the additional purchase of energy can be reduced to a minimum. The own consumption should be steered in such a way that no energy peaks originate with the fed into the public grid. So it must be given to the system with which priority the different consumers have to be supplied with energy. Also time intervals must be fixed in which they are allowed to do their duties.

The farmer must be able to intervene in the control any time to prevent perhaps disadvantages in the matter of well-being of the animals. In spite of the high mechanization degree or level of automation, the welfare of the animals must still come first. Besides, the supply of the farm must be also guaranteed with longer failure of the public electricity network by uncoupling of this.

On the subject on-farm-energy management system in dairy cattle, no research operations or results are known currently.

\subsubsection{Behavior}

Behavioral changes often conclude by a stress response reaction. Under identical conditions, every individual reacts differently to a stressor [2].

Sambraus [3] evaluates the activity changes, by which animals do not show their daily rhythm any more, typical for kind of preliminary stages of behavioral disorder and reactions to stressors. Also the change of frequency of specific behavior patterns can be due to stress. Besides, animals should look longer and more often for a situation to be able to explain a certain behavior, e.g., standing longer in a cubicle before lying down. Also, incomplete movements or uncompleted activities can be clues to possible stress reactions.

\subsubsection{Activity Behavior}

Normally the movement activity of cows in loose-houses is rather low; nevertheless, it increases while the cows are in heat. Local changes mostly appear only if dairy cattle visit the different functional areas, for example, with the feed admission. Winckler [4] assumes that dairy cattle in the stable travel up to four kilometers daily.

Koch et al. [5] measured the movement activity of Holstein Friesian and Simmental cattle heifers with pedometers. The main conclusion of this experiment was an average value of 9,660 steps within $24 \mathrm{~h}$ and no race influence could be ascertained. Data of animals in heat were not incorporated, because in the estrus a clearly increased activity was to be observed. In a study with 200 cows, an activity of animals not in heat of 50 steps/h did arise; this corresponds to 1,200 steps/d [6].

\subsubsection{Eating Behavior}

There are a lot of possible influences on the eating behavior. It is a matter of fact that not only the stable system, the technology and the way the farmer runs his farm have a major impact, also the psychologies of the animal itself and the harmony inside the group has influences in eating behavior.

This also can be found in Scheibe [7] as he considers the saturation state, the age, the live weight, the stage of lactation of the animal and the race to be important. Moreover, animal feeding place ratio, feed places and also the stable climate are decisive.

Schrader and Mayer [8] see the connection among food quality, chewing beats and rumination time.

A decrease of the remasticating is the first sign for a 
physiological disorder. After the calving, the remasticating should increase bit by bit to indicate a good feed admission and digestion (500 min) [9].

\subsubsection{Lying Behavior}

The total lying time amounts about $10 \mathrm{~h}$ according to Sambraus [10]. According to Muchow [11], dairy cattle lie in the loose-house on an average $720 \mathrm{~min}$ daily. Nygaard [12] mentions an everyday lying duration in the loose-house of approximately $708 \mathrm{~min}$ and Kaiser [13] of $680 \mathrm{~min}$. Scheibe [7] describes seven to 11 lying periods and a whole downtime of approximately 550-650 min in a stable position. The lying duration is often looked as a graduation about well-being; however, high downtimes can also express stress reactions. On this occasion, the environmental factors mentioned above play an important role. Because cows change their body side with the lying, they should show no couch periods of more than two hours on the one and same side [7].

\section{Materials and Methods}

\subsection{Experimental Design}

This paper is the first part of a major study to the quantification of possible stress reactions with dairy cattle by a temporarily energy-conditioned failure of an AMS. Besides, the heart activity and the faecal cortisol metabolite concentrations were measured and the behavior of the animals was taped by video technology.

The experiment was carried out on two different farms with which 12 dairy cattle were selected by chance for the investigation (focus cows). Six days before data admission, the heart rate sensor belts were put on to the animals for measurement of the heart activity, so that they could get used to them (habituation). The period of the data capturing applied about two weeks per farm, and every basal measurement took $3 \mathrm{~d}$ and the test measurement $4 \mathrm{~d}$ (Fig. 1). The basal measurement showed the state of the animals without any influence of an energy-conditioned failure of the AMS.

For the real test measurement, the usual milking behavior of the focus cows was analyzed and then the respective focus cow's admittance to the AMS was refused unique within $24 \mathrm{~h}$ for only $2 \mathrm{~h}$ at the first test day. On the second test day, the granted right of milking was hereby extended to $4 \mathrm{~h}$ to raise the likelihood of an AMS refusal. On both next test days, the granted right of milking was fixed animal-individually from $2 \mathrm{~h}$ to maximum $4 \mathrm{~h}$, not to

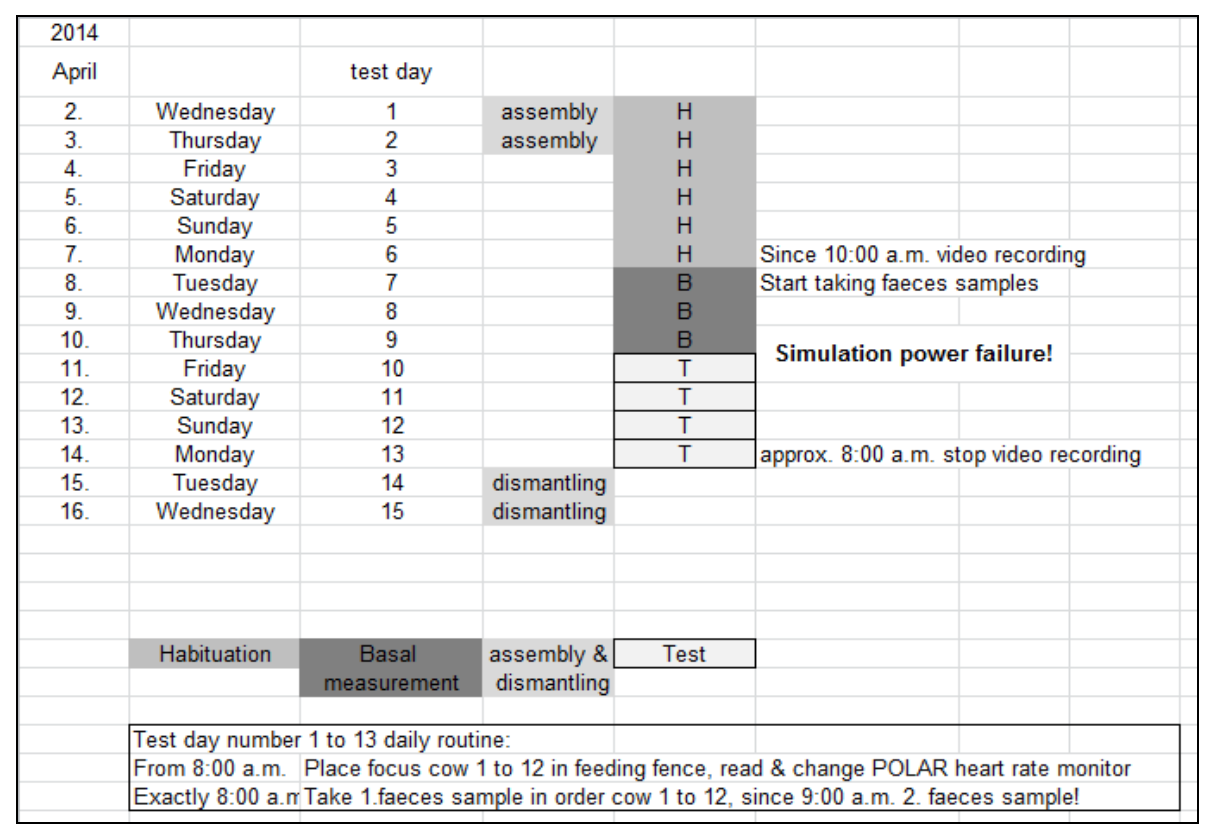

Fig. 1 Experimental design farm 1. 
overload the udder and not to lower the milk amount achievement.

\subsubsection{Test Farms and Animals}

The first test farm (B1) operates a loose-housing stable with resting pens for 60 milk cows of the race Simmental Fleckvieh breed. They used the milking system Lely Astronaut A3. The basic feed presentation occurred up to six times a day with an automatic feeding conveyor belt.

The second test farm (B2) also operates a loose-housing stable but with resting pens for 68 milk cows of the race Simmental Fleckvieh breed. They used the milking system Lely Astronaut A4. The basic feed presentation occurred up to six times a day with a fodder mixing vehicle.

At each farm twelve animals were selected by chance (focus cows) and then equipped with the necessary measuring technique (Fig. 2).

The experiments are to be continued on three other farms in the course of this year.

\subsubsection{Measurement Heart Activity}

For the measurement of the heart activity, products of the Company Polar were used. The wireless textile sensor "Equine H2" was used as a measuring belt. The elastic belt was fastened around the breast behind the shoulder of the animal. Two electrodes integrated in the measuring belt, in the distance of approximately half a meter, grasped the heart activity. The electrodes were placed on the left side of the test animal near the scapula and the breastbone. The body spots at which the electrodes were fixed, had been shaved to support the measurements in B1 and with a customary electrode gel provided; in B2 a shave was renounced and only the electrode gel was used. The electrode gel supported the conduction of electrical impulses. The measuring belts were covered for the protection with the second broader belt (customary horse blanket belt).

"WearLink ${ }^{\circledR}$ " transferred the measuring data, at a $2.4 \mathrm{GHz}$ rate, on a pulse clock of the brand "Polar Equine RS800CX trainings computer”. This pulse clock recorded the heart rate (blows/min) and the RR intervals $\left(10^{-3} \mathrm{~s}\right)$ over more than $24 \mathrm{~h}$. The training computer was kept in a small box of plastic which was screwed to the measuring belt.

Each morning at approximately 8:00 o'clock, the laboratory animals were pushed in cubicles and were locked up with a rope (B1) or fixed in the feeding fences (B2) to insert or to change the pulse watches. Because the training computers only have one storage capacity of maximum $40.5 \mathrm{H}$, the memory of the pulse watches had to be saved every day. In accordance of

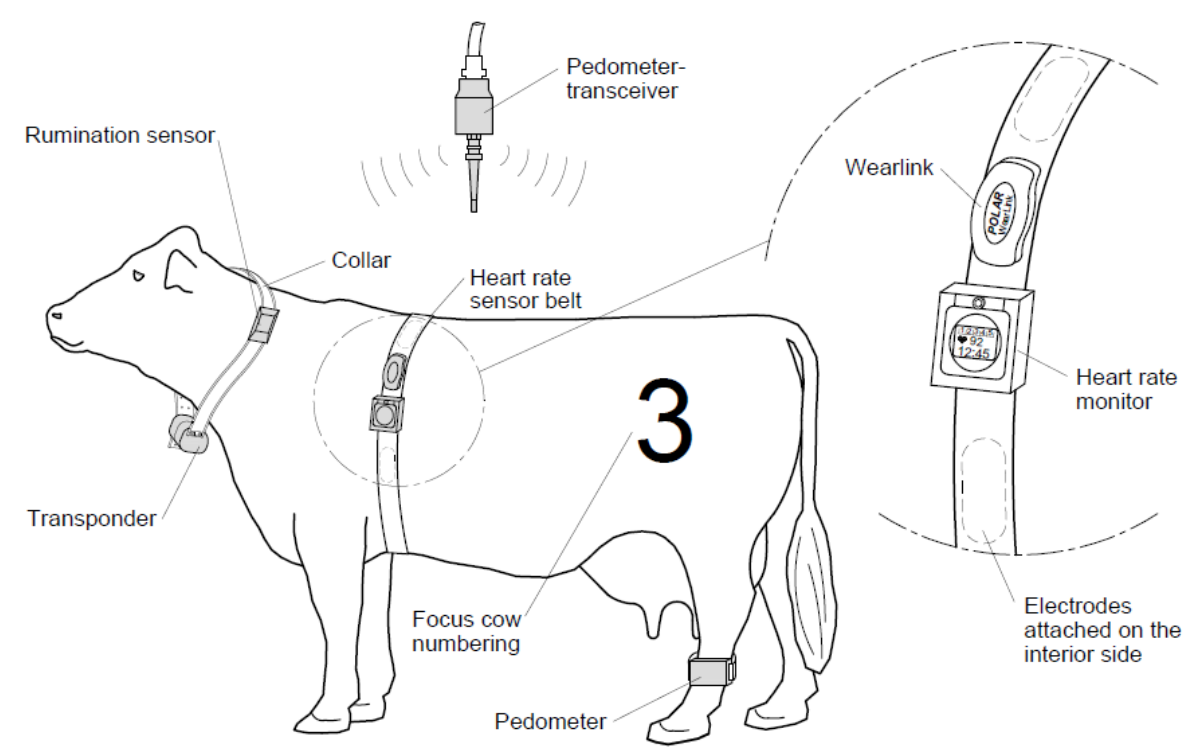

Fig. 2 Measuring technique at a focus cow in animal-machine-interactions. 
an infrared adaptor "IrDA of USB adaptors", the heart rate and RR intervals was transferred (Polar) by the pulse clock to the computer. With regular controlling, an examination of the breast belts was carried out by the respective farmer to avoid any failures by the data recording by slipped belts.

\subsubsection{Behavioral Observation}

In every stable, several video cameras (Mobotix) were installed to the behavioral admission. These recorded the area around the AMS day and night, and the feed table and infrared searchlights were necessary for the night images.

In the stable of B1, 10 cameras recorded the behavior. In stable of B2, seven cameras were installed.

\subsubsection{Measurement of Movement Activities}

In addition to the video analysis with ALT Pedometer, the movement activity and lying time were recorded; ALT is short for activity, lying time and temperature.

\section{Results}

For a comprehensive on-farm-energy-management system, the scientific foundations have to be developed, transformed into prototypes and be tested in practice. Concrete solutions should be developed by the inclusion of regenerative energy sources, including intelligent network access and by intensive investigation of the animal-machine-interactions for "Integrated Dairy Farming".

Upon the termination of all experiments on the five farms and evaluation of all test results in this sub-project, possible stress reactions should be shown by dairy cattle with a possible energy-conditioned failure of milking robots. The test results should give explanation, whether variations or failures in the energy supply have effects on the cow behavior or whether postponements in the usual daily routine, e.g., in the milking routine cause stress reactions to the milk cows.

Therefore, ethological criteria can be validated to a quantitative and qualitative analysis. Moreover, the behavior patterns-appropriate for animal species in an increasingly automated process of engineering in a dairy farm, can be evaluated while taking autonomous control options within the scope of a comprehensive On-farm-energy-management system into account.

\section{Discussion}

For an exact analysis of all electrical consumers of a modern dairy production, the bases for their smart-grid binding and the development of a central

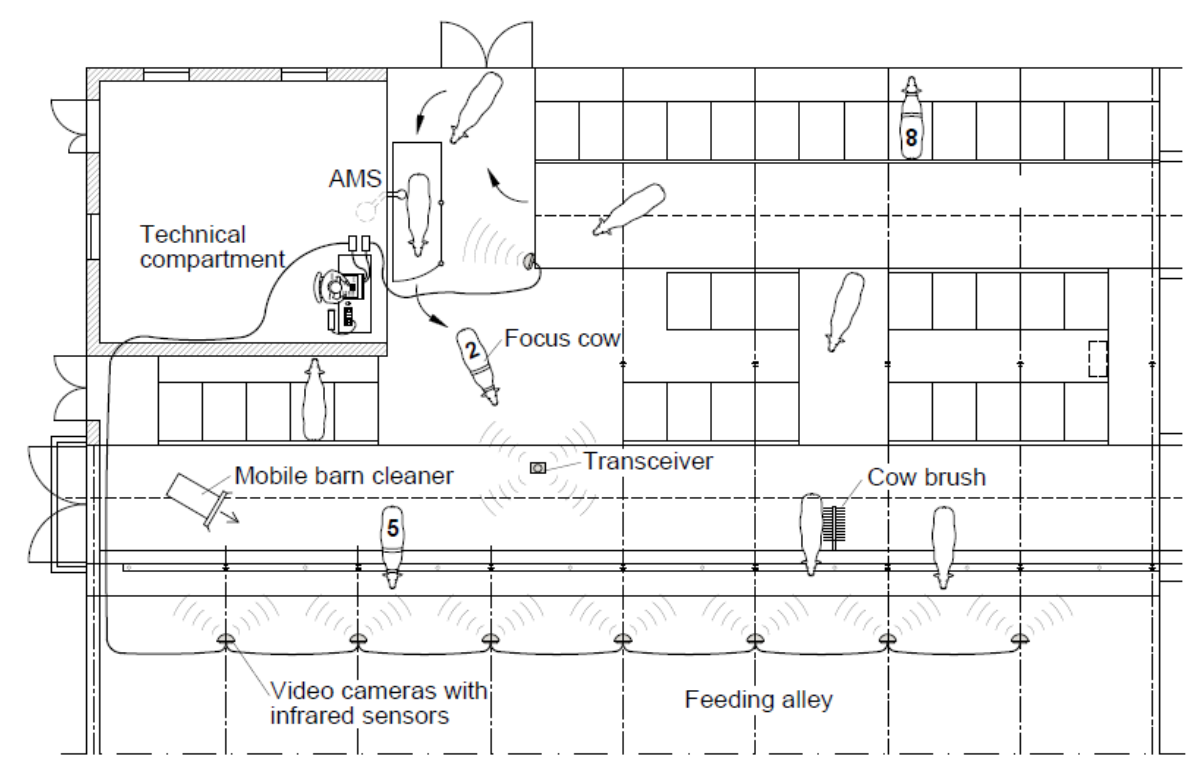

Fig. 3 Construction of an experimental dairy farm concerning animal-machine-interactions. 
monitoring and control module must be compiled first. After a next simulation phase with simultaneous externally supported hard and software development, the installation and extensive series of experiments on an everyday farm intended for it are planned.

Nevertheless, it is not to be calculated on the fact that few manufacturers of automatic milking and feeding technology will agree in close future on a bus-system on dairy farms. Hence, it cannot be intervened directly in the machine control. For every device available in the market, a data sheet must be provided which contains the relevant system data (e.g., power consumption, application time). Above all, it must contain the priority, with which the device must be supplied with stream. Then on account of these data sheets, all manufacturers can be integrated into the on-farm-energy-management system. Afterwards, the bases should play an important role onto a prototype of an energy-management system, which could be developed by an industrial partner who considers the priorities and the temporal flexibility of the consumers.

The prototype will be installed on an everyday farm and its function will be tested by experiments.

\section{References}

[1] German Federal Ministry of Economics and Technology (BMU) and German Federal Ministry for Economic Affairs and Energy (BMWi). 2010. Guidelines for a Clean, Reliable and Affordable Energy Supply. German: BMU and BMWi, 3-5. (in German)

[2] Keeling, L., and Jensen, P. 2009. “Abnormal Behavior, Stress and Welfare." In The Ethology of Domestic Animals: An Introductory Text, 2nd ed., edited by Jensen,
P. Wallingford, Oxfordshire: CAB International, 89-93.

[3] Sambraus, H. H. 1978. Ethology of Domestic Animals. Berlin, Hamburg: Paul Parey Publishing Company, 113-20. (in German)

[4] Winckler, C. 2009. "Behaviour of Cattle.” In Behaviour of Cattle, edited by Hoy, S. Stuttgart: Ulmer Publishing Company, 96-7. (in German)

[5] Koch, K., Pirchner, F., and Graf, F. 1995. "Physiological Measures and Movement Activity of Fleckvieh and Holstein-Friesian Cattle during Summer in the Mountains.” Berlin and Munich Veterinary Weekly Script 108: 1-7. (in German)

[6] Fürstenberg, L., Lühr, J., and Gottheit, B. 1996. "Heat Identification with Pedometer.” Practicing Vet. 4: 330-3. (in German)

[7] Scheibe, K. M. 1987. Behaviour of Domestic Animals, Cattle, Pig and Sheep. 2nd ed., Jena: VEB Gustav Fischer Publishing Company. (in German)

[8] Schrader, L., and Mayer, C. 2009. "Behaviour.” In Cattle Breeding and Milk Production: Recommendations for Practice. Braunschweig: Wilfried Brade and Gerhard Flachowsky, 65-77. (in German)

[9] SCR Dairy. 2013. "Rumination Monitoring." White Paper, Netanya, Israel, Accessed May 16, 2014. http://www.de.scrdairy.com/images/PDF/Rum_12_A4_E ng_Nov13_low.pdf.

[10] Grauvogl, A., and Sambraus, H. H. 1990. "Applied Behaviour at Domestic Cattle 'Behaviour of Cattle'." Presented at Conference of Experts in Behavioral Research, March 20-22, Grub Near Munich. (in German)

[11] Muchow, P. 1968. "Influence of Social Decline in Behaviour of Dairy Cattle of Holstein-Friesian Cattle in Loose-House Stable with Particular Focus of the Milk Production.” M.Sc. thesis, Karl-Marx-University, Leipzig. (in German)

[12] Nygaard, A. 1969. "Behavior Studies in Different Types of Barns.” In Proceeding of VII. Congress Commission Internationale du Gènie Rural, Baden-Baden, 113.

[13] Kaiser, R. 1971. "Performance Respond and Behaviour of Dairy Cattle in Large Group Management on Slatted Floor.” Mh. Vet. and Med. 26: 726. (in German) 